\title{
Invloed educatie op praktijk vrijheidsbeperking
}

\author{
Author(s) \\ Doedens, Paul \\ DOI \\ 10.1007/s41184-019-0120-3
}

Publication date

2019

Document Version

Final published version

Published in

TVZ - Verpleegkunde in praktijk en wetenschap

Link to publication

Citation for published version (APA):

Doedens, P. (2019). Invloed educatie op praktijk vrijheidsbeperking.

TVZ - Verpleegkunde in praktijk en wetenschap, 129(6), 50-51.

https://doi.org/10.1007/s41184-019-0120-3

It is not permitted to download or to forward/distribute the text or part of it without the consent of the author(s) and/or copyright holder(s), other than for strictly personal, individual use, unless the work is under an open content license (like Creative Commons).

\section{Disclaimer/Complaints regulations}

If you believe that digital publication of certain material infringes any of your rights or (privacy) interests

please let the Library know, stating your reasons. In case of a legitimate complaint, the Library will make the material inaccessible and/or remove it from the website. Please contact the library:

https://www.amsterdamuas.com/library/contact/questions, or send a letter to: University Library (Library of the University of Amsterdam and Amsterdam University of Applied Sciences), Secretariat, Singel 425, 1012 WP Amsterdam, The Netherlands. You will be contacted as soon as possible. 


\section{Invloed educatie op praktijk vrijheidsbeperking}

auteur

PAUL DOEDENS

verpleegkundige, promovendus bij Amsterdam UMC, locatie AMC, afdeling Psychiatrie en docent-onderzoeker, Hogeschool van Amsterdam, faculteit Gezondheid, opleiding Verpleegkunde

\section{CONTEXT}

In Turkije (waar onderhavig onderzoek wordt uitgevoerd) krijgt 23,9 procent van de psychiatrisch patiënten te maken met fysieke fixatie. Kavak e.a. onderzochten het effect van een educatieve interventie op de kennis, attitude en praktijk van psychiatrisch verpleegkundigen met betrekking tot het toepassen van fysieke fixatie. ${ }^{1}$ Eerder onderzoek heeft uitgewezen dat kennis en attitude invloed heeft op het gebruik van fysieke fixatie. ${ }^{2,3}$

De definitie van fysieke fixatie is het beperken van de bewegingsvrijheid van individuen door fysieke of mechanische dwangmaatregelen. Hierbij moet men denken aan fysiek vasthouden (holding) of mechanische fixatie met banden op bed of stoel. Ondanks dat deze interventie wordt toegepast voor de eigen veiligheid van patiënten brengt fysieke fixatie veel risico's met zich mee, zoals trauma's, aspiratie, fysieke verwondingen en zelfs overlijden. Psychiatrisch verpleegkundigen ervaren schuldgevoelens na het toepassen van fixatie en worstelen met de bijbehorende ethische dilemma's.

\section{DOELSTELLING}

In dit onderzoek wordt de effectiviteit van een educatieve interventie onderzocht op de verbetering van de kennis, attitude en vaardigheden van psychiatrisch verpleegkundigen.

\section{METHODE}

Het onderzoek is uitgevoerd in een instelling voor geestelijke gezondheidszorg (ggz) in de regio Oost-Anatolië in Turkije. De instelling bestaat uit twaalf klinieken die gesitueerd zijn in aparte gebouwen. Verpleegkundigen konden aan het onderzoek deelnemen als zij toestemming gaven tot deelname, als zij in de laatste zes maanden in een van de klinieken werkzaam waren en als zij ooit zelf fysieke fixatie hadden toegepast. In totaal werden 250 van de 278 verpleegkundigen uit de instelling benaderd voor deelname. De auteurs hebben een sample size berekening gemaakt. Hieruit kwam dat men verwachtte minimaal 106 participanten (53 voor zowel de interventie- als controlegroep) nodig te hebben om een eventueel effect aan te tonen. Er was sprake van clusterrandomisatie op het niveau van de klinieken, waarbij de randomisatie met een computerprogramma werd uitgevoerd. De uitkomstmaat was de uitkomst op de 'Levels of Knowledge, Attitudes, and Practices of Nurses Regarding Physical Restraints Questionnaire', een gevalideerde schaal om kennis (score tussen de 0 en 11), attitude (score tussen de 12 en 48) en vaardigheden (score tussen de 14 en 42) op het gebied van fysieke fixatie te meten. ${ }^{4}$ Een hogere score op deze schaal betekent meer kennis over fixatie, een positieve attitude om fixatie te voorkomen en betere vaardigheden voor het uitvoeren van fixatie. De vragenlijst werd bij zowel de interventie- als controlegroep voor en na het toepassen van de interventie door een van de auteurs geanalyseerd. De interventie bestond uit een educatieve interventie over fysieke fixatie van twaalf groepsbijeenkomsten, gedurende zes weken. Onderwerpen waren communicatie, weten regelgeving, praktijk van fixatie, empathievaardigheden en agressiemanagement. De controlegroep kreeg geen interventie. Gemiddelde scores werden tussen de groepen vergelijken, evenals de gemiddelde score van beide groepen voor en na de interventie.

\section{RESULTATEN}

Verpleegkundigen $(n=126)$ werden gerandomiseerd voor de interventie- of controlegroep, waarna er 15 uitvielen. In de interventiegroep vielen 10 verpleegkundigen uit omdat ze hun toestemming introkken of niet participeerden aan de groepsbijeenkomsten. De interventiegroep $(n=53)$ en controlegroep $(n=58)$ waren vergelijkbaar en op de voormeting van het meetinstrument werden geen verschillen gevonden. In de controlegroep vielen 5 verpleegkundigen uit, de reden daarvan is onbekend. De controlegroep toonde geen verschil tussen de voor- en nameting op de domeinen kennis, attitude en vaardigheden. In de experimentele groep werden wél statistisch significante verschillen $(p<0,05)$ tussen de voor- en nameting op alle drie de domeinen gevonden. De gemiddelde verschillen die werden gevonden waren op het domein kennis 2,57 punten ( $\mathrm{p}<0,001)$, op het domein attitude 4,07 punten $(\mathrm{p}<$ $0,001)$ en op het domein vaardigheden 8,09 punten $(p<0.001)$. Daarnaast behaalden de verpleegkundigen uit de experimen- 


\section{KRITISCH BEKEKEN}

tele groep gemiddeld een significant hogere score op alle drie domeinen $(p<0,001)$ vergeleken met de deelnemers uit de controlegroep.

\section{BESCHOUWING}

Deze RCT met relatief kleine onderzoekspopulatie heeft gekozen voor clusterrandomisatie. Gezien de aard van de interventie (een meerdaagse training) is dat verstandig, om beïnvloeding van de participanten uit de controlegroep door participanten uit de interventiegroep (contaminatie) te voorkomen. Echter, alle participanten werkten in dezelfde instelling, dus contaminatie is niet geheel te voorkomen. In deze studie is het onmogelijk om de participanten te blinderen. De

\section{'Concrete interventies ontwikkeld in de ggz kunnen aan de basis staan voor het ontwikke- len van een strategie voor ziekenhuizen en verpleeghuizen'}

interventie en de uitkomstmeting werden uitgevoerd door een van de onderzoekers. Er is dus waarschijnlijk helemaal geen sprake van blindering, terwijl blindering van de uitkomstmeting tot de mogelijkheden behoorde door dit door een buitenstaander te laten uitvoeren. Er werd gebruik gemaakt van een gevalideerde schaal, maar de literatuur over dit meetinstrument bleek schaars en onduidelijk is of er een adequate vertaling in het Turks is gebruikt voor dit specifieke onderzoek. Al met al is de interne validiteit van voldoende niveau. De resultaten wijzen op een klein, maar positief effect van de interventie.

In Nederland wordt fixatie in de ggz nauwelijks gebruikt, in tegenstelling tot separatie. ${ }^{5}$ Het aantal separaties is in Nederland veel lager (7,0 procent) dan het aantal fixaties in Turkije (23,9 procent). ${ }^{6}$ De generaliseerbaarheid naar de Nederlandse situatie is daarom beperkt.
$\mathrm{Al}$ jaren is er veel aandacht voor het verminderen van dwangmaatregelen in de psychiatrie, waardoor de verbetering van de kennis en attitude van verpleegkundigen door educatie in Nederland minder groot zal zijn dan in Turkije. Er is in Nederland namelijk al veel gerealiseerd. Daarnaast toont deze studie geen direct verband aan tussen verbeterde kennis en attitude enerzijds en vermindering van fixatie anderzijds. Desondanks stelt deze studie een concrete interventie voor ter verbetering van kennis, attitude en vaardigheden ten aanzien van fysieke fixatie. Voor de Nederlandse ggz is dit wellicht minder van belang, maar fixatie komt nog wel veel voor in de Nederlandse ziekenhuizen en verpleeghuizen. In de komende jaren zal het gebruik van vrijheidsbeperkende interventies in de ziekenhuizen verder in beeld worden gebracht met de Basisset Medisch Specialistische Zorg Indicatoren. ${ }^{7}$ Concrete interventies die zijn ontwikkeld in de ggz kunnen aan de basis staan voor het ontwikkelen van een strategie voor de ziekenhuizen en verpleeghuizen om het gebruik van vrijheidsbeperkende interventies verder terug te dringen.

水水水水

\section{REFERENTIES}

1. Kavak F, Yilmaz E, Okanli A, e.a. The effect of psychoeducation given to psychiatry nurses on level of knowledge, attitudes, and practices regarding physical restraint: A randomized controlled study. Perspect Psychiatr Care. 2019; Epub ahead of print.

2. Khalil Al, Al Ghamdi MAM, Al Malki S. Nurses' knowledge, attitudes, and practices toward physical restraint and seclusion in an inpatients' psychiatric ward. Int J Cult Ment Health. 2017;10(4):44767.

3. Laukkanen $E$, VehvilainenJulkunen K, Louheranta 0, e.a. Psychiatric nursing staffs' attitudes towards the use of containment methods in psychiatric inpatient care: An integrative review. Int J Ment Health Nurs. 2019; 28(2):390-406.
4. Suen KPL. Knowledge, attitude and practice of nursing home staff towards physical restraints in Hong Kong nursing homes. Asian Journal of Nursing Studies. 1999;5(2):73-86. 5. Bak J, Aggernaes H. Coercion within Danish psychiatry compared with 10 other European countries. Nord J Psychiatry. 2012;66(5) 297-302.

6. Noorthoorn EO, Voskes Y, Janssen WA, et al. Seclusion Reduction in Dutch Mental Health Care: Did Hospitals Meet Goals? 2016;67(12):1321-7.

7. IGJ. Basisset Medisch Specialistische Zorg Kwaliteitsindicatoren 2019. Beschikbaar via: https:// www.igj.nl/documenten/indicatorensets/2017/01/01/basisset-medischspecialistische-zorg. Psychiatric Services.

\section{Conclusie}

Een educatieve interventie over fysieke fixatie voor verpleegkundigen om de kennis, attitude en vaardigheden van verpleegkundigen te doen toenemen is in
Turkije effectief gebleken. De Nederlandse ggz levert al jaren grote inspanningen om het aantal dwangmaatregelen te laten afnemen, daardoor is dit onderzoek beperkt generaliseerbaar naar de Nederlandse situatie. Het geeft echter wel aanknopingspunten voor onderzoek in Nederland naar de kennis, houding en vaardigheden ten aanzien van dwang, zowel in de ggz als in andere sectoren waar vrijheidsbeperkende interventies helaas nog onderdeel zijn van de dagelijkse praktijk. 